\title{
Resinas poliméricas reticuladas com ação biocida: atual estado da arte
}

\section{Crosslinked polymer resins with biocide action: state-of-the-art}

\author{
Luciana Cunha Costa ${ }^{1}$, Maria Aparecida Larrubiua Granado Moreira Rodrigues Mandu², \\ Luiz Claudio de Santa Maria² e Mônica Regina da Costa Marques²*
}

\author{
${ }^{1}$ Centro Setorial de Ciências Biológicas e da Saúde, Centro Universitário Estadual da Zona Oeste - UEZO, \\ Rio de Janeiro, RJ, Brasil \\ ${ }^{2}$ Departamento de Química Orgânica, Instituto de Química, Universidade do Estado do Rio de Janeiro - \\ UERJ, Rio de Janeiro, RJ, Brasil \\ *monicamarques@uerj.br
}

\begin{abstract}
Resumo
Copolímeros reticulados à base de divinilbenzeno vêm sendo extensivamente empregados como suportes de catalisadores e complexantes de íons metálicos, adsorventes de compostos orgânicos e fases estacionárias em separações cromatográficas. A introdução de grupos biocidas a estes materiais é relatada em patentes desde a década de 1970, contudo apenas a partir do ano 2000 estes copolímeros passaram a ser aplicados também como suportes para grupos biocidas. A presente revisão apresenta as principais combinações de suportes poliméricos e grupos biocidas estudados com o objetivo de preparar resinas biocidas reticuladas. Procura-se estabelecer relação entre as características dessas resinas e seu mecanismo de ação biocida.
\end{abstract}

Palavras-chave: agentes antimicrobianos imobilizados em polímeros, biocida, copolímeros de estireno-divinilbenzeno, resinas poliméricas.

\begin{abstract}
Crosslinked copolymers of divinylbenzene have been extensively employed as supports for catalysts and chelating groups of metal ions, adsorbents of organic compounds and stationary phases for chromatography separations. The use of these copolymers as support for biocidal groups is reported in patents since the 1970s, but only after 2000 were these copolymers also applied as supports for biocidal groups. This paper describes the main combinations of polymeric supports and biocide groups employed in biocide polymer resins. The relationship between the characteristics of these resins and their mechanism of action is also established in this work.
\end{abstract}

Keywords: antimicrobial agents immobilized on polymers, biocide, styrene-divinylbenzene copolymers, polymeric resins.

\section{Introdução}

A contaminação por micro-organismos pode causar sérias complicações para o homem, particularmente se estiver em equipamentos médicos, cirúrgicos, odontológicos, medicamentos, produtos de higiene e de cuidados com a saúde, sistemas de purificação de água, tecidos, embalagens e estocagem de alimentos ${ }^{[1,2]}$.

Uma maneira de combater as atividades microbianas negativas é através de agentes biocidas. "Biocida" é um termo genérico utilizado para se referir aos compostos dotados da capacidade de inibir o crescimento ou matar determinados micro-organismos. A aplicação desta classe de materiais é muito ampla, podendo ser utilizados nos mais diversos produtos e processos, e por isso outros termos são utilizados para diferenciá-los entre si: antibióticos, antissépticos, desinfetantes e conservantes ${ }^{[3]}$.

Percebe-se que há uma confusão conceitual quanto à atividade do agente antimicrobiano. $\mathrm{O}$ termo biocida só deve ser utilizado quando ocorrer a destruição significativa dos micro-organismos e o termo bioestático ou bacteriostático quando ocorrer a inibição do crescimento dos micro-organismos, sem que no entanto estes sejam destruídos ${ }^{[4,5]}$. Os agentes biocidas podem exercer efeitos tanto bacteriostáticos quanto bactericidas. Os mecanismos de ação responsáveis por esses efeitos podem diferir. Efeitos bacteriostáticos são geralmente considerados quando causam algum dano metabólico que é reversível pela remoção ou neutralização do agente, 
enquanto que a ação bactericida resulta de danos irreparáveis e irreversíveis à estrutura ou função vital celular ${ }^{[5]}$.

A escolha do grupo biocida adequado deve levar em consideração a natureza da bactéria e o provável mecanismo de ação deste agente. As bactérias do grupo coliforme, por serem gram-negativas, apresentam além da membrana citoplasmática uma camada adicional constituída de lipopolissacarídeos que confere a elas uma maior integridade estrutural. Esta camada adicional é uma barreira para a atuação direta de agentes biocidas. Nestes casos, a membrana citoplasmática normalmente é o local predisposto a ataque de agentes biocidas. Uma vez que, é na membrana citoplasmática das células gram-negativas e gram-positivas que ocorrem as interações balanceadas entre os fosfolipídeos e as proteínas enzimáticas e estruturais. Esta situação de equilíbrio garante uma impermeabilidade controlada e a organização topológica pela qual a homeostase intracelular e o transporte e metabolismo vetorial são mantidos. O citoplasma também é um local muito importante, onde ocorrem muitos processos catabólicos e anabólicos, contudo por ser mais externa a membrana é mais sujeita à ação de bactericidas ${ }^{[6]}$.

Agentes antimicrobianos de baixa massa molecular são comumente usados na esterilização de água e solo e na preservação de alimentos ${ }^{[7]}$. Estes agentes, de forma geral, apresentam muitas desvantagens tais como a toxicidade residual e capacidade antimicrobiana de curto prazo devido à dificuldade no controle da taxa de difusão ${ }^{[6-8]}$. O método de cloração da água, por exemplo, leva a formação de compostos orgânicos clorados, tais como trialometanos (THM), quando da reação do cloro. Diversos estudos apontam que esses compostos são carcinogênicos ${ }^{[9]}$. O ozônio também é outro agente de baixa massa molecular muito utilizado. Este composto apresenta como principal desvantagem a sua instabilidade, o que dificulta o seu transporte e armazenamento, exigindo que seja gerado in situ por meio de um processo dispendioso ${ }^{[10-14]}$.

Como a toxidade residual é elevada mesmo quando estes agentes antimicrobianos de baixa massa molecular são usados na quantidade adequada ${ }^{[7,15]}$, uma série de polímeros antimicrobianos vem sendo desenvolvidos visando minimizar este problema.

Dentre as formas de preparação de polímeros antimicrobianos está a introdução de grupos bactericidas em suportes poliméricos e dentre os suportes poliméricos estudados encontram-se os copolímeros reticulados à base de divinilbenzeno. A imobilização de grupos bactericidas em copolímeros de divinilbenzeno, visando a preparação de resinas biocidas reticuladas, vêm atraindo cada vez mais a atenção dos pesquisadores. Entretanto, não são encontrados na literatura trabalhos de revisão que versam especificamente sobre o desenvolvimento destas resinas. Por este motivo, este trabalho de revisão apresenta as principais metodologias adotadas para a preparação de resinas biocidas reticuladas e procura estabelecer uma correlação entre o mecanismo de ação das resinas poliméricas biocidas e as características dos micro-organismos estudados.

\section{Polímeros Reticulados com Atividade Biocida}

De acordo com Kenawy ${ }^{[7]}$, um polímero antimicrobiano ideal deve possuir como características principais os seguintes parâmetros: síntese fácil e economicamente viável; estabilidade em longo prazo para uso e armazenagem na temperatura da aplicação pretendida; insolubilidade em água para aplicação em processos de desinfecção de água; não se decompor e/ou emitir produtos tóxicos; possibilidade de ser regenerado quando perder sua atividade; e ser biocida para um amplo espectro de micro-organismos patogênicos em curtos tempos de contato. Infelizmente, muitas destas características não têm sido estudadas pelos pesquisadores que se propõem a desenvolver novos polímeros antimicrobianos. A avaliação do tempo de vida útil dos polímeros, por exemplo, tem sido negligenciada em muitos trabalhos e o estudo da ação biocida limita-se quase sempre ao emprego de Escherichia coli e de bactérias gram-positivas como Staphylococcusaureus, não sendo avaliadas outras espécies de micro-organismos como vírus e fungos ${ }^{[15]}$.

De acordo com Siedenbiedel e Tiller ${ }^{[16]}$, polímeros antimicrobianos podem se dividir em três grupos:

- os polímeros biocidas (biocidal polymer): são preparados pela introdução de grupos biocidas a estruturas poliméricas preparadas previamente (suportes);

- os biocidas poliméricos (polymeric biocide): são polímeros cujas unidades repetitivas (meros) possuem ação biocida; e

- polímeros que liberam biocidas (biocide-releasing polymers): são materiais nos quais a porção polimérica atua meramente como carreadora do biocida ${ }^{[16]}$.

Embora esta distinção sugerida por Siedenbiedel e Tiller ${ }^{[16]}$ seja muito importante, a maioria dos pesquisadores não a utiliza, tratando diferentes materiais simplesmente como polímeros biocidas.

Resinas poliméricas vêm sendo extensamente avaliadas como suportes, sobretudo para catalisadore ${ }^{[17-23]}$ e complexantes de íons metálicos ${ }^{[24-31]}$. A aplicação desses materiais como suportes para agentes biocidas tem sido relatada em diversas patentes desde a década de $70^{[10,32-44]}$. Na maioria destas patentes é descrita a preparação de complexos de transferência de carga com iodo imobilizados em resinas poliméricas reticuladas à base de estireno-divinilbenzeno (Sty-DVB). Estes materiais são indicados em processos de desinfecção de água e de fluidos biológicos. Entretanto, só a partir do ano 2000, foi que estes materiais começaram a ser extensivamente aplicados como suportes para grupos biocidas, introduzindo um novo campo de aplicação para copolímeros reticulados.

Outros suportes poliméricos mais hidrofílicos, como por exemplo, copolímeros de ácido metacrílico ${ }^{[45]}$ e poli(metacrilato de glicidila $)^{[15]}$ também estão sendo modificados com grupos que possuem atividades biocidas. A principal vantagem para emprego destes suportes está relacionada a sua maior capacidade de inchamento em água, meio em que os micro-organismos normalmente se encontram. O desinteresse por estes materiais é normalmente justificado pelo maior custo, em relação aos clássicos copolímeros 
Sty-DVB. Não foram encontrados estudos comparativos de avaliação da ação biocida de copolímeros de diferentes graus de hidrofilicidade funcionalizados com os mesmos grupos biocidas. Estudos desta natureza seriam importantes para dimensionar o efeito do grau de hidrofilicidade dos suportes sobre a eficiência biocida das resinas.

Os agentes biocidas normalmente introduzidos aos substratos poliméricos derivam de uma variedade de classes químicas (Tabela 1). Dentre os grupos biocidas mais estudados, destacam-se os sais de amônio e fosfônio quaternários $[1,7,8,11,12,16,46-62]$, os complexos de transferência de carga envolvendo grupos amônio quaternário e iodo ${ }^{[10,12,13,32-44,47,63-66]}$, as N-haloaminas ${ }^{[7,47,67-76]}$, derivados de fenóis e ácido benzóico ${ }^{[50,77,78]}$, sulfoderivados ${ }^{[46,47,79-81]}$. Além destes grupos, é comum também a introdução de compostos inorgânicos antimicrobianos aos polímeros, especialmente nanopartículas de prata ${ }^{[9,47,82-84]}$. A escolha destes agentes biocidas é normalmente feita com base em um conhecimento prévio da ação germicida ou bacteriostática dos compostos de baixa massa molecular ${ }^{[10]}$.

Polieletrólitos catiônicos ou poliquats incluem os polímeros contendo grupos amônio, fosfônio, piridínio, anilínio, amidínio, guanidínio, tiourônio, imidazólio, diazônio, carbênio e sulfônico, dentre outros ${ }^{[82]}$. Os polímeros contendo grupos amônio, fosfônio e piridínio são indiscutivelmente os biocidas poliméricos mais explorados na literatura ${ }^{[47]}$. A ação biocida dos outros grupos catiônicos tem sido pouco explorada $^{[1,7,12,15,16,47-62]}$. O mecanismo mais aceito de ação biocida dos polímeros poliquats é baseado na interação destrutiva entre os grupos quaternários e a parede celular e/ou membrana citoplasmática. O polímero contendo estes grupos é atraído pelos fosfolipídios, constituintes da membrana celular, carregados negativamente. As camadas de fosfolipídios são então redistribuídas através da interação com o material bactericida que possuem múltiplos centros carregados positivamente; em função disso ocorre um deslocamento dos fosfolipídios e desorganização da arquitetura da membrana, provocando a liberação de constituintes celulares e consequentemente morte da bactéria $^{[2,16,46,47,49,52,54,59]}$.

Em diversos trabalhos que tratam do desenvolvimento de resinas poliquats é feita a avaliação da influência do comprimento da cadeia alquil quaternário sobre a eficiência biocida do produto ${ }^{[46,50,51,53-57,59,60]}$. Como exemplo deste tipo de estudo é possível citar o trabalho de Jiang e colaboradores ${ }^{[56]}$. Estes autores prepararam uma série de resinas contendo grupos amônio quaternário fazendo a graftização de aminas terciárias trietilamina, tripropilamina, tributilamina e trioctilamina a um copolímero Sty-DVB clorometilado. A atividade antimicrobiana das resinas foi avaliada contra a bactéria gram-positiva $S$. aureus por meio de ensaios em batelada. O polímero graftizado com trioctilamina apresentou maior eficiência bactericida seguida por tributilamina, tripropilamina e trietilamina. Os autores sugerem que o aumento do tamanho da cadeia substituinte gera um aumento da hidrofobicidade do polímero e consequentemente favorece a interação com a membrana citoplasmática causando a morte da bactéria.

Em um estudo semelhante, $\mathrm{Lu}$ e colaboradores ${ }^{[50]}$ realizaram uma comparação entre a capacidade biocida de monômeros funcionalizados com sais de amônio e fosfônio quaternário e polímeros preparados a partir da polimerização destes monômeros. Este tipo de comparação não é comum na literatura, talvez porque julga-se que um

Tabela 1. Estrutura dos polímeros biocidas comumente estudados ${ }^{[10,47,67,77]}$.

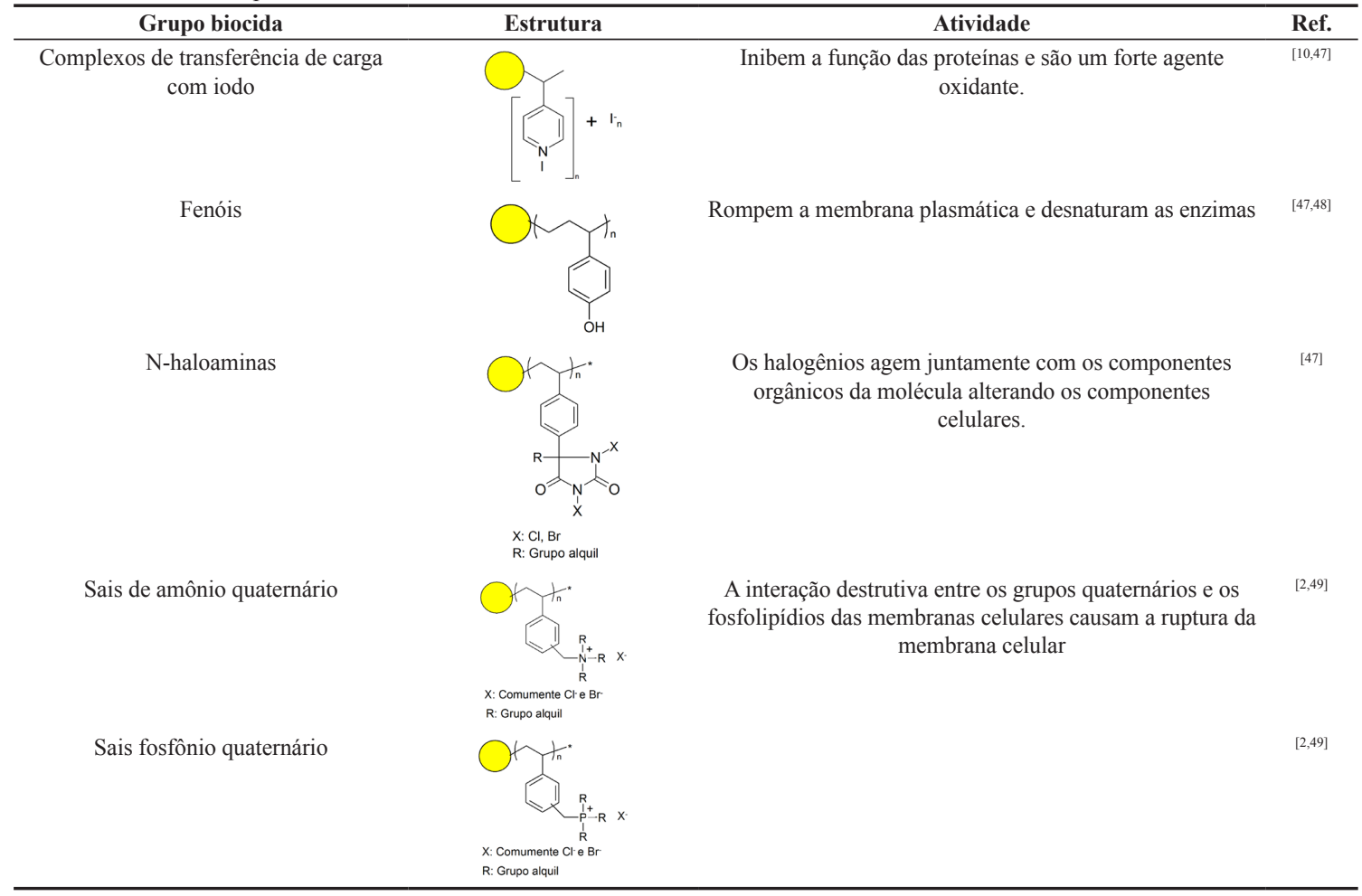


biocida polimérico tenha sempre menor capacidade que um monômero biocida, por conta do impedimento estérico que o polímero oferece para o contato com as bactérias ou a difusão do agente biocida no meio. No estudo de $\mathrm{Lu}$ e colaboradores ${ }^{[50]}$ os monômeros sais de amônio quaternário foram sintetizados pela quaternização de metacrilato de dimetilaminoetila (DMAEMA) com diferentes haletos orgânicos: cloreto de benzila (BC), brometo de butila (BB), brometo de dodecila (DB) e brometo de hexadecila (HB). A homopolimerização destes monômeros modificados gerou os biocidas denominados DMAEMA-BC, DMAEMA-BB, DMAEMA-DB e DMAEMA-HB respectivamente. A ação biocida dos monômeros e polímeros amônio quaternário aumentou com o aumento da cadeia carbônica. Os autores também comprovaram que os polímeros DMAEMA-BC e DMAEMA-BB, preparados a partir da quaternização de DMAEMA com os haletos de alquila de cadeia menor (cloreto de benzila e brometo de butila, respectivamente), apresentaram maior eficiência biocida que os monômeros quaternizados precursores. Já os polímeros DMAEMA-DB e DMAEMA-HB, quaternizados com os haletos de alquila de cadeia maior (brometo de dodecila e brometo de hexadecila, respectivamente), mostraram menor ação biocida que os monômeros de origem. Os autores não fornecem explicações para estes dados.

A capacidade desinfetante de iodo e de seus derivados é reportada por diferentes autores, assim como o uso de materiais catiônicos com propriedades bactericidas ${ }^{[10-13,32-44,63-66]}$. O iodo é conhecido como agente antimicrobiano, pois apresenta facilidade em penetrar na parede celular dos micro-organismos, inibindo a sua síntese vital. É bem conhecido que moléculas de piridina (Py) reagem com iodo formando um complexo molecular estável do tipo n-s, denominado complexo de transferência de carga (CTC). O iodo apresenta uma forte tendência a formar estes complexos mesmo com doadores fracos. Tais complexos usualmente apresentam contribuição de estruturas carregadas e, frequentemente, $\mathrm{I}^{3-} \mathrm{e} \mathrm{I}^{5-}$ resultam destas interações ${ }^{[10]}$. Devido à facilidade de ancorar o iodo em copolímeros contendo grupos amônio quaternário, o interesse no uso do iodo como desinfetante tem aumentado muito nos últimos anos ${ }^{[10,12,13,64,65]}$.

Em estudos realizados por Jandrey e colaboradores ${ }^{[10,64,65]}$ foi avaliada a influência da composição monomérica do copolímero de 2-vinilpiridina-estireno-divinilbenzeno (2-Vpy-Sty-DVB) sobre a ação biocida dos complexos de transferência de carga entre o iodo e o nitrogênio da 2-Vpy. Três copolímeros com razões molares entre os monômeros 2-Vpy-Sty-DVB de 70/00/30; 70/10/20 e 70/20/10, respectivamente, foram preparados e impregnados com iodo. Todos os materiais sintetizados neste trabalho foram testados contra suspensão de $E$. coli, em diferentes concentrações iniciais de célula bacterianas $\left(10^{3}\right.$ a $10^{7}$ células $\left.\mathrm{mL}^{-1}\right)$. Os copolímeros não modificados não apresentaram atividade bactericida, enquanto que os seus respectivos complexos poliméricos com iodo apresentaram excelente atividade bactericida. Para esses copolímeros, os pesquisadores sugerem que o mecanismo de ação bactericida envolva interações entre os complexos de transferência de carga e a parede celular negativamente carregada das células de $E$. coli ${ }^{[10,64,65]}$.

De acordo com o mecanismo de ação, as resinas biocidas podem ser classificadas em desinfetantes poliméricos insolúveis de contato (IPCD, do inglês, Insoluble Polymeric Contact Disinfectants) e desinfetantes de liberação de demanda (DRD, do inglês, Demand Release Disinfectants) ${ }^{[10]}$. As resinas poliméricas que apresentam atividade biocida pelo contato são principalmente resinas de troca aniônica, incluindo as resinas com grupo amônio e fosfônio quaternário. Nesse caso, acredita-se que a interação entre os microorganismos e o polímero desinfetante ocorra através da carga negativa presente na superfície celular e as cargas positivas na superfície dos polímeros ${ }^{[9,46]}$. Por outro lado, as resinas do tipo DRD liberam o agente biocida que é difundido após o contato do polímero com o meio e interage com os micro-organismos. Comumente neste caso, o agente biocida encontra-se na forma de contra-íon ou composto de baixa massa molecular disperso na matriz polimérica ${ }^{[47,48]}$.

A capacidade antibacteriana dos IPCD está estritamente relacionada à acessibilidade da solução contaminada aos grupos biocidas presentes na matriz polimérica, enquanto para os polímeros DRD a eficiência está relacionada a capacidade de difusão do agente antimicrobiano no meio. Tanto o acesso das bactérias aos agentes biocidas quanto à difusão destes agentes biocidas são controlados pelas características morfológicas do suporte ${ }^{[10,12]}$.

Valle e colaboradores ${ }^{[12,13]}$ estudaram copolímeros à base de $2 \mathrm{Vpy}$, na razão molar 2-Vpy-Sty-DVB de $70 / 10 / 20$, mas variando a composição da mistura diluente: tolueno/n-heptano $=50 / 50$ e 70/30, obtendo dessa forma, polímeros com morfologiasvariadas. Estes copolímeros foram quaternizados com iodeto de metila e acrilonitrila e posteriormente impregnados com iodo. $\mathrm{O}$ fator morfológico que contribuiu mais significativamente para a atividade biocida dos produtos finais foi a capacidade de inchamento em meio aquoso. Os copolímeros não modificados não apresentaram ação bactericida significativa contra E. coli, entretanto os copolímeros quaternizados com iodeto de metila ou acrilonitrila mostraram uma pequena ação biocida. O copolímero de menor porosidade, aquele preparado com composição diluente 50/50, com maior capacidade inchamento em água e quaternizado com iodeto de metila foi o mais ativo (superior a 17\% para todas as concentrações de $E$. Coli testadas $-10^{3}-10^{7}$ células $\mathrm{mL}^{-1}$ ). A incorporação de iodo aos copolímeros quaternizados forneceu materiais com elevada atividade biocida. Os testes de estabilidade demonstraram que estes copolímeros impregnados com iodo são agentes de liberação de demanda (DRD). A maior parte desses copolímeros liberou iodo no meio capaz de matar as células $E$. coli. Contudo, esse fato não pode ser encarado como prejudicial à proposta do material sintetizado, uma vez que a concentração de iodo liberada no meio era ínfima e ocorreu de forma gradativa ${ }^{[12,13]}$.

Os trabalhos de Jandrey e colaboradores ${ }^{[10,64,65]}$, Valle e colaboradores ${ }^{[12,13]}$ são interessantes porque procuram estabelecer uma relação entre a eficiência das resinas biocidas e as características de porosidade dos suportes poliméricos precursores. Como já comentado, a capacidade antibacteriana das resinas poliméricas são dependentes não apenas das características físico químicas dos grupos biocidas, mas também das características morfológicas do suporte polimérico que suporta estes grupos. A maioria dos trabalhos que tratam do desenvolvimento de polímeros biocidas se limita a desenvolver uma metodologia para a 
preparação do polímero e avaliação da capacidade biocida. A relação entre as características morfológicas dos suportes poliméricos e a capacidade biocida das resinas é na maioria das vezes negligenciada ${ }^{[24,30]}$.

O grupo N-haloamina é outro grupo muito estudado e que tem se mostrado eficiente contra uma grande variedade de micro-organismos tais como vírus, bactérias, fungos e leveduras ${ }^{[7,48,68]}$. N-haloaminas são definidos como compostos contendo uma ou mais ligações covalentes nitrogênio-halogênio, formadas pela cloração de grupos imida, amida ou amina ${ }^{[48]}$. A introdução destes grupos a suportes poliméricos é comumente realizada a partir da reação desses suportes com anéis heterocíclicos de 5 e 6 membros contendo grupos funcionais amida e imida, seguida de halogenação ${ }^{[7,48,68]}$. O mecanismo de ação biocida proposto para polímeros contendo grupos N-haloamina é baseado no contato entre os grupos funcionais e o micro-organismo, o que resulta na liberação do halogênio e morte do micro-organismo ${ }^{[51]}$. Uma das principais vantagens para a sua aplicação tem sido a sua estabilidade ao $\mathrm{pH}$ do meio. $\mathrm{O}$ grupo $\mathrm{N}$-haloamina<smiles>C=CCN1C(=O)NC(C)(C)C1=O</smiles>

$\mathrm{ADMH}$

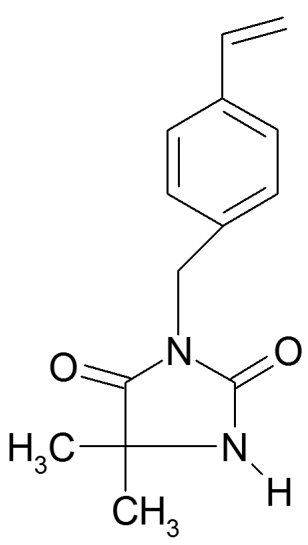

VBDMH
Figura 1. Estrutura química dos monômeros vinílicos de hidantoína 3-alil-5,5-dimetil-hidantoína (ADMH) e 3-(4'-vinilbenzil)-5,5-dimetil-hidantoína (VBDMH) ${ }^{[76]}$. é muito estável, não se decompõem em água para formar produtos tóxicos e não libera halogênio no meio até que ocorra o contato com o micro-organismo ${ }^{[7,11,47,69]}$.

Sun e $\mathrm{Sun}^{[76]}$ introduziram grupos N-haloamina a copolímeros de Sty-DVB fazendo a copolimerização de Sty e DVB com os monômeros vinílicos de hidantoína: 3-alil-5,5-dimetil-hidantoína $(\mathrm{ADMH})$ e 3-(4'-vinilbenzil)-5,5-dimetil-hidantoína (VBDMH) (Figura 1). Os copolímeros obtidos foram tratados com uma solução de cloro com o objetivo de transformar os grupos hidantoína em N-haloamina. As propriedades biocidas dos derivados N-haloamina foram examinadas contra bactérias gram-negativa e gram-positiva, E. coli e $S$. aureus, respectivamente. Pelos resultados obtidos, os autores observaram maior atividade biocida contra $E$. coli, para ambos os derivados N-haloamina, oque foi justificado em função das diferenças estruturais das membranas citoplasmática das bactérias ${ }^{[76]}$.

O grupamento fenólico também é conhecidamente considerado como um agente biocida contra uma série de micro-organismos. Estes compostos danificam as membranas celulares e ocasionam a liberação dos constituintes intracelulares ou causam coagulação intracelular dos constituintes citoplasmáticos, provocando à morte da célula ${ }^{[47]}$.

Jeong e colaboradores ${ }^{[78]}$ estudaram a atividade biocida dos produtos de reação de copolímeros alternados de estireno-anidrido maleico (SMA) com 4- aminofenol (AP) contra as bactérias gram-negativa e gram-positiva $E$. coli e S. aureus, respectivamente (Figura 2). Tanto o copolímero modificado SMA-AP quanto o reagente 4-aminofenol mostraram fortes atividades bactericidas contra os dois tipos de bactérias. A atividade do copolímero contra E. coli foi ligeiramente mais baixa que contra $S$. aureus, sugerindo que o polímero pode ter limitações de difusão através da parede celular das bactérias gram-negativas. Além disso, o reagente 4-aminofenol apresentou maior ação biocida que o polímero SMA-AP, o que foi atribuído a sua maior facilidade de difusão através das paredes celulares das bactérias ${ }^{[78]}$.

Resinas poliméricas contendo grupos sulforados vêm sendo extensamente avaliadas em relação à capacidade complexante de íons metálicos ${ }^{[23,30]}$. Embora os sulfoderivados possuam conhecida ação biocida, a capacidade biocida de<smiles>CC(CC(CC(C)(C)c1ccccc1)C1C(=O)OC(=O)C1C)C1CCCCCCC1</smiles>

SMA<smiles>Nc1ccc(O)cc1</smiles>

AP<smiles>CC(C(=O)O)C(CC(C(=O)Nc1ccc(O)cc1)C(C)(C)C)C(=O)Nc1ccccc1</smiles>

SMA-AP

Figura 2. Reação entre copolímeros alternados de estireno-anidrido maleico (SMA) com 4- aminofenol (AP) visando a preparação do copolímero modificado SMA-AP ${ }^{[78]}$. 
resinas contendo estes grupos ainda é muito pouco explorada na literatura. $\mathrm{O}$ desenvolvimento de resinas com essa dupla funcionalidade, capacidade complexante de íons metálicos e ação biocida é extremamente interessante do ponto de vista ecológico e ambiental.

Recentemente Souza e colaboradores ${ }^{[79]}$ incorporaram grupos sulfofosforila a um copolímero à base de Sty-DVB a partir da fosforilação destes copolímeros com $\mathrm{PCl}_{3} / \mathrm{AlCl}_{3}$ seguida de reação com $\mathrm{CS}_{2}$ em meio básico (Figura 3). Essas resinas tiveram sua ação biocida avaliadas contra suspensões de $E$. Coli nas concentrações de $10^{3}-10^{7}$ células $/ \mathrm{mL}$. Tanto o produto da primeira etapa (fosforilação) quanto da segunda etapa (formação do grupamento sulfofosforila) apresentaram ação biocida em torno de $100 \%$ até a concentração de $10^{5}$, a partir dessa concentração o material sulfofosforilado apresentou uma eficiência em torno de $80 \%$ enquanto o fosforilado caiu para $20 \%{ }^{[79]}$.

Costa e colaboradores ${ }^{[80]}$ avaliaram a capacidade biocida de uma resina polimérica hiperreticulada contendo grupos ditiocarbamato. A resina hiperreticulada utilizada neste trabalho foi a resina comercial MN-250 produzida pela Purolite SRL. A preparação da resina ditiocarbamato seguiu a metodologia clássica baseada na nitração dos anéis benzênicos, redução dos grupos nitro e reação dos grupos amino com dissulfeto de carbono. Os produtos dessas reações foram submetidos à avaliação da capacidade bactericida contra suspensão de $E$. coli nas concentrações de $10^{3}-10^{7}$ células $/ \mathrm{mL}$. A resina comercial e os produtos das reações de nitração e redução não apresentaram ação biocida para nenhuma das concentrações de $E$. Coli avaliadas. Já a resina contendo grupos ditiocarbamato mostrou ação biocida significativa para todas as concentrações de $E$. Coli estudadas, sendo que para a concentração de $10^{3}$ células $/ \mathrm{mL}$ a ação biocida foi de $92 \%{ }^{[80]}$.

Também tem sido estudada a capacidade biocida de compósitos e nanocompósitos metálicos preparados a partir da introdução de partículas metálicas a resinas reticuladas à base de $\mathrm{DVB}^{[85-87]}$. Os estudos de nanomateriais bactericidas são particularmente oportunos considerando o recente aumento de novas linhagens de bactérias resistentes aos mais potentes antibióticos e as potencialidades das partículas em escala manométricas ${ }^{[88]}$.

Dentre os agentes antimicrobianos inorgânicos, a prata tem sido empregada mais extensivamente ${ }^{[47,86]}$. Embora a ação biocida da prata seja muito bem conhecida, o seu mecanismo de atuação bactericida é somente entendido parcialmente ${ }^{[87]}$. Muitos estudos têm sugerido que o mecanismode atuação bactericida envolva a interação dos íons prata com macromoléculas biológicas. Íons prata trocam o $\mathrm{H}^{+}$dos grupos sulfidrila e tiol, inativando as proteínas, diminuindo a permeabilidade da membrana e causando a morte da célula. Outros estudos têm mostrado mudanças estruturais evidentes na membrana celular, bem como a formação de pequenos grânulos com densidade eletrônica formados pela prata e o enxofre ${ }^{[50]}$

Santa Maria e colaboradores ${ }^{[84]}$ prepararam nanocompósitos de prata fazendo a incorporação de nanopartículas de prata a duas resinas comerciais:Amberlyst ${ }^{\circledR} 15$ WET; e Lewatitt ${ }^{\circledR}$ VPOC1800, ambas resinas sulfônicas, porém com características de porosidade diferenciadas: a primeira macroporosa; e a segunda do tipo gel. A incorporação de nanopartículas de prata às resinas foi feita através de impregnação inicial de íons $\mathrm{Ag}^{+}$(tratamento das resinas sulfônicas com $\mathrm{AgNO}_{3}$ ) seguida de redução com $\mathrm{NH}_{4} \mathrm{OH}$ na presença de agente protetor (solução gelatina-hidroxietilcelulose). Os compósitos obtidos foram avaliados quanto a sua atividade bactericida contra $E$. colinas concentrações entre $10^{3}$ a $10^{7}$ celulas $\mathrm{mL}^{-1}$. As atividades bactericidas de todos os compósitos de prata foram significativas, indicando que este metal realmente é eficaz como agente antimicrobiano. De uma forma geral, a atividade biocida decresceuem função do aumento da concentração de bactérias. Esse fato possivelmente pode ser atribuído à saturação do copolímero, já que as soluções foram eluídas sempre na mesma coluna recheada com a resina impregnada com prata. Isto significa que até a eluição da concentração $10^{7}$ célulasmL ${ }^{-1}$ de E.coli, mais de $10^{15}$ células já haviam passado pela coluna e devem ter formado um biofilme ao redor das pérolas que prejudicaram a interação da prata com novas bactérias ${ }^{[84]}$.

Gangadharan e colaboradores ${ }^{[45]}$ também estudaram a ação biocida de resinas impregnadas com prata, mas introduziram nanopartículas de prata a um copolímero de ácido metacrílico reticulado com DVB. A introdução das nanoparticulas de prata foi feita através de tratamento dos copolímeros com solução de $\mathrm{AgNO}_{3}$ seguida de redução química com boroidreto de sódio. O compósito obtido foi avaliado quanto a sua atividade bactericida empregando o teste de zona de inibição contra duas bactérias gram- negativas (E. coli e Pseudomonas aeruginosa) e duas gram-positivas (S. aureus eBacillus subtilis). Para todas as bactérias houve presença de um halo de inibição, indicando poder bactericida ${ }^{[45]}$.

As propriedades bactericidas da prata, em adição às características dos polímeros como resistência mecânica e baixa massa específica, fornecem atributos únicos as resinas impregnadas com nanopartículas de prata, que garantem vantagens em relação às técnicas atualmente utilizadas para desinfetar a água ${ }^{[84,87]}$. Contudo, torna-se importante avaliar a toxicidade deste metal tanto para o meio ambiente quanto para o ser humano, além da avaliação da estabilidade dessas resinas, se ocorre uma possível lixiviação do metal introduzido na matriz polimérica ${ }^{[10,12,13,64,65,87]}$. Sendo partículas extremamente pequenas, as nanopartículas de prata devem possuir uma capacidade de deslocamento por todo o meio ambiente considerável, o que as tornam disponíveis tanto na atmosfera, no meio aquático, bem como no solo ${ }^{[88,89]}$. Assim, são necessárias mais informações acerca da sua toxicidade e determinação dos níveis seguros de exposição, para que

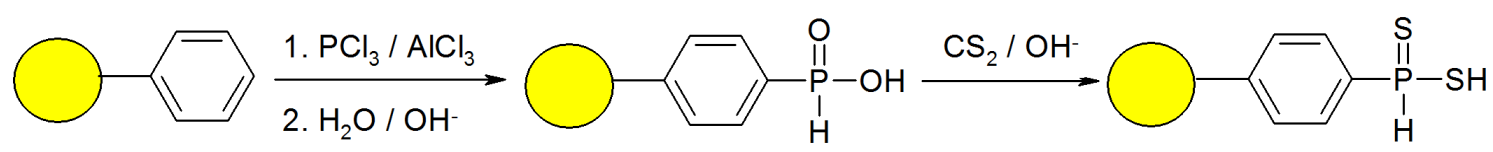

Figura 3. Rota para a introdução de grupos sulfofosforila a copolímeros Sty-DVB ${ }^{[79]}$. 
as resinas impregnadas com nanopartículas de prata possam ser utilizadas no tratamento de águas.

A maioria dos trabalhos que estuda a ação biocida de resinas poliméricas avalia a ação bacteriológica destes materiais por meio de testes de halo de inibição e/ou ensaios em batelada. Os estudos que utilizam ensaios em batelada como método de avaliação biocida quase sempre não exploram variações de massa de resina, tempo de contato e concentração de bactérias no meio. Estes dados são de grande importância para efeitos de comparação da ação biocida dessas resinas e auxiliam no desenvolvimento de novos materiais mais eficientes.

Por se tratarem de materiais infusíveis e insolúveis, as resinas biocidas e nanocompósitos biocidas podem ser utilizados em processo de colunas, e estas colunas podem ser reutilizadas após uma simples regeneração. Dessa forma, o elevado custo inicial do material é recuperado em curto prazo, fazendo com que a relação custo/benefício deste processo de tratamento de águas seja economicamente viável ${ }^{[14]}$. Os estudos em coluna são muito pouco explorados na literatura, entretanto alguns dados obtidos a partir destes estudos, tais como, ponto de ruptura, capacidade de trabalho, são extremamente importantes do ponto de vista de aplicação das resinas biocidas em macro escala.

\section{Conclusões}

Resinas biocidas preparadas a partir da introdução de grupos biocidas a suportes poliméricos reticulados apresentam grande potencial para tratamento de águas contaminadas com micro-organismos patogênicos. Dentre os grupos biocidas incorporados às resinas poliméricas percebe-se que há um grande interesse pelos grupos amônio e fosfônio quaternário, grupos N-haloamina e nanocompósitos de prata. A capacidade biocida de resinas contendo grupos sulfurados ou outras nanopartículas metálicas têm sido ainda pouco explorada na literatura, embora muitos desses compostos possuam conhecida ação biocida. Sabe-se que as propriedades antibacterianas das resinas biocidas estão relacionadas não só com a capacidade bactericida dos grupos, mas também com a distribuição adequada desses grupos ativos na superfície da rede polimérica. Por este motivo, é de grande relevância o estudo para obter suportes poliméricos com estrutura físico-química que favoreça o contato com os micro-organismos ou a difusão do biocida no meio. Há alguns trabalhos na literatura que tem se esforçado neste sentido, procurando estabelecer relações entre as características morfológicas dos suportes poliméricos e a capacidade biocida das resinas produzidas a partir destes suportes. Contudo, são necessários estudos mais detalhados de influência do grau de porosidade e capacidade de inchamento dos suportes poliméricos sobre a capacidade biocida das resinas.

\section{Agradecimentos}

Fundação Carlos Chagas Filho de Amparo à Pesquisa do Estado do Rio de Janeiro (FAPERJ), Coordenação de Aperfeiçoamento de Pessoal de Nível Superior (CAPES) e Conselho Nacional de Desenvolvimento Científico e Tecnológico $(\mathrm{CNPq})$ pelo apoio financeiro.

\section{Referências}

1. Gottenbos, B., van der Mei, H. C., Klatter, F., Nieuwenhuis, P., \& Busscher, H. J. (2002). In vitro and in vivo antimicrobial activity of covalently coupled quaternary ammonium silane coatings on silicone rubber. Biomaterials, 23(6), 14171423. http://dx.doi.org/10.1016/S0142-9612(01)00263-0. PMid:11829437.

2. Huang, J., Murata, H., Koepsel, R. R., Russell, A. J., \& Matyjaszewski, K. (2007). Antibacterial polypropylene via surface-initiated atom transfer radical polymerization. Biomacromolecules, 8(5), 1396-1399. http://dx.doi.org/10.1021/ bm061236j. PMid:17417906.

3. Mc Donnel, G., \& Russel, A. D. (1999). Antiseptics and disinfectants: activity, action, and resistance. Clinical Microbiology Reviews, 12(1), 147-179.

4. Amato, V., No., Nicodemo, A. C., \& Lopes, H. V. (2007). Antibióticos na prática clínica. São Paulo: Sarvier.

5. Denyer, S. P. (1995). Mechanisms of action of antibacterial biocides. International Biodeterioration \& Biodegradation, 36(34), 227-245. http://dx.doi.org/10.1016/0964-8305(96)00015-7.

6. Denyer, S. P., \& Stewart, G. S. A. B. (1998). Mechanisms of action of disinfectants. International Biodeterioration \& Biodegradation, 41(3-4), 261-268. http://dx.doi.org/10.1016/ S0964-8305(98)00023-7.

7. Kenawy, R., Worley, S. D., \& Broughton, R. (2007). The chemistry and applications of antimicrobial polymers: a stateof-the-art review. Biomacromolecules, 8(5), 1359-1384. http:// dx.doi.org/10.1021/bm061150q. PMid:17425365.

8. Denyer, S. P., \& Maillard, J. H (2002). Cellular impermeability and uptake of biocides and antibiotics in gram-negative bacteria. Journal of Applied Microbiology, 92(S1), 35-45. http://dx.doi. org/10.1046/j.1365-2672.92.5s1.19.x

9. Hu, F. X., Neoh, K. G., Cen, L., \& Kang, E. T. (2005). Antibacterial and antifungal efficacy of surface functionalized polymeric beads in repeated applications. Biotechnology and Bioengineering, 89(4), 474-484. http://dx.doi.org/10.1002/ bit.20384. PMid:15609269.

10. Jandrey, A. C. (2007). Desenvolvimento de resinas a base de 2-vinil-piridina contendo iodo e sua avaliação como agente bactericida (Tese de doutorado). Instituto Militar de Engenharia, Brasil.

11. Kawabata, N. (1992). Capture of micro-organisms and viruses by pyridinium-type polymers and application to biotechnology and water purification. Progress in Polymer Science, 17(1), 1-34. http://dx.doi.org/10.1016/0079-6700(92)90015-Q.

12. Valle, A. S. S., Costa, L. C., Marques, M. R. C., Silva, C. L. P., Santa Maria, L. C., Merçon, F., \& Aguiar, A. P. (2011). Preparação de copolímeros à base de 2-vinilpiridina com propriedades bactericidas. Quimica Nova, 34(4), 577-583. http://dx.doi.org/10.1590/S0100-40422011000400005.

13. Valle, A. S. S., Marques, M. R. C., Costa, L. C., Santa Maria, L. C., Aguiar, A. P., \& Mercon, F. (2013). Evaluation of bactericidal action of 2-vinylpiridine copolymerscontaining quaternary ammonium groups and their charge transfer complexes. Polímeros: Ciência e Tecnologia, 23(2), 152-160. http://dx.doi.org/10.1590/S0104-14282013005000023.

14. Qu, X., Alvarez, P. J. J., \& Li, Q. (2013). Applications of nanotechnology in water and wastewater treatment. Water Research, 47(12), 3931-3946. http://dx.doi.org/10.1016/j. watres.2012.09.058. PMid:23571110.

15. Kenawy, El-R, Abdel-Hay, F. I., El-Raheem, A., El-Shanshoury, R., \& El-Newehy, M. H. (1998). Biologically active polymers: synthesis and antimicrobial activity of modified glycidyl methacrylate polymers having a quaternary ammonium and phosphonium groups. Journal of Controlled Release, 50(1-3), 
145-152. http://dx.doi.org/10.1016/S0168-3659(97)00126-0. PMid:9685881.

16. Siedenbiedel, F., \& Tiller, J. C. (2012). Antimicrobial polymers in solution and on surfaces: overview and functional principles. Polymers, 4(1), 46-71. http://dx.doi.org/10.3390/polym4010046.

17. Rezende, S. M., Reis, M. C., Reid, M. G., Silva, P. L., Jr., Coutinho, F. M. B., San Gil, R. A. S., \& Lachter, E. R. (2008). Transesterification of vegetable oils promoted by poly(styrenedivinylbenzene) and poly(divinylbenzene). Applied Catalysis A, General, 349(1-2), 198-203. http://dx.doi.org/10.1016/j. apcata.2008.07.030.

18. Flores, K. O. V., Aguiar, A. P., Aguiar, M. R. M. P., \& Santa Maria, L. C. (2007). Microwave assisted Friedel-Crafts acylation reactions of Amberlite XAD-4 ${ }^{\mathrm{TM}}$ resin. Materials Letters, 61(4-5), 1190-1196. http://dx.doi.org/10.1016/j. matlet.2006.06.081.

19. Coutinho, F. M. B., Rezende, S. M., \& Soares, B. G. (2006). Characterization of sulfonated poly(styrene-divinylbenzene) and poly(divinylbenzene) and its application as catalysts in esterification reaction. Journal of Applied Polymer Science, 102(4), 3616-3627. http://dx.doi.org/10.1002/app.24046.

20. Rezende, S. M., Soares, B. G., Coutinho, F. M. B., Reis, S. C., Reid, M. G., Lachter, E. R., \& Nascimento, R. S. V. (2005). Aplicação de resinas sulfônicas como catalisadores em reações de transesterificação de óleos vegetais. Polímeros: Ciência e Tecnologia, 15(3), 186-192. http://dx.doi.org/10.1590/S010414282005000300008

21. Coutinho, F. M. B., Aponte, M. L., Barbosa, C. C. R., Costa, V. G., Lachter, E. R., \& Tabak, D. (2003). Resinas sulfônicas: síntese, caracterização e avaliação em reações de alquilação. Polímeros: Ciência e Tecnologia, 13(3), 141-146. http://dx.doi. org/10.1590/S0104-14282003000300003.

22. Coutinho, F. M. B., \& Rezende, S. M. (2001). Catalisadores sulfônicos imobilizados em 2013 síntese, caracterização e avaliação. Polímeros: Ciência e Tecnologia, 11(4), 222-233. http://dx.doi.org/10.1590/S0104-14282001000400012.

23. Cunha, L., Coutinho, F. M. B., \& Gomes, A. S. (2004). Suportes poliméricos para catalisadores sulfônicos: síntese e caracterização. Polímeros: Ciência e Tecnologia, 14(1), 31-37. http://dx.doi.org/10.1590/S0104-14282004000100011.

24. Souza, M. A. V., Santa Maria, L. C., Costa, M. A. S., Wang, S. H., Costa, L. C., Araujo, H. C., Jr., \& Amico, S. C. (2011). Synthesis, characterization and evaluation of phosphorylated resins in the removal of $\mathrm{Pb} 2+$ from aqueous solutions. Polymer Bulletin, 67(2), 237-249. http://dx.doi.org/10.1007/s00289010-0373-z.

25. Costa, L. C., Gomes, A. S., Coutinho, F. M. B., \& Teixeira, V. G. (2010). Chelating resins for mercury extraction based on grafting of polyacrylamide chains onto styrene-divinylbenzene copolymers by gamma irradiation. Reactive \& Functional Polymers, 70(10), 738-746. http://dx.doi.org/10.1016/j. reactfunctpolym.2010.07.003.

26. Costa, L. C., Coutinho, F. M. B., Teixeira, V. G., \& Gomes, A. S. (2007). Principais rotas de síntese de resinas complexantes de mercúrio. Polímeros: Ciência e Tecnologia, 17(2), 145-157. http://dx.doi.org/10.1590/S0104-14282007000200014.

27. Novais, M. H., Aguiar, A. P., Aguiar, M. R. M. P., \& Santa Maria, L. C. (2006). Synthesis of porous copolymers network based on methyl methacrylate and evaluation in the $\mathrm{Cu}$ (II) extraction. Materials Letters, 60(11), 1412-1415. http://dx.doi. org/10.1016/j.matlet.2005.11.039.

28. Dutra, P., Toci, A., Riehl, C., Barbosa, C., \& Coutinho, F. M. B. (2005). Adsorption of some elements from hydrochloric acid by anion Exchange. European Polymer Journal, 41(8), 1943-1946. http://dx.doi.org/10.1016/j.eurpolymj.2004.10.023.
29. Cassella, R. J., Magalhães, O. I. B., Couto, M. T., Lima, E. L. S., Neves, M. A. F. S., \& Coutinho, F. M. B. (2005). On-line preconcentration and determination of $\mathrm{Zn}$ in natural water samples employing a styrene-divinylbenzene functionalized resin and flame atomic absorption spectrometry. Analytical Sciences, 21(8), 939-944. http://dx.doi.org/10.2116/analsci.21.939. PMid: 16122164.

30. Teixeira, V. G., Coutinho, F. M. B., \& Gomes, A. S. (2004). Resinas poliméricas para separação e pré-concentração de chumbo. Quimica Nova, 27(5), 754-762. http://dx.doi. org/10.1590/S0100-40422004000500015.

31. Santa Maria, L. C., Amorim, M. C. V., Aguiar, M. R. M. P., Guimarães, P. I. C., Costa, M. A. S., de Aguiar, A. P., Rezende, P. R., de Carvalho, M. S., Barbosa, F. G., Andrade, J. M., \& Ribeiro, R. C. C. (2001). Chemical modification of crosslinked resin based on acrylonitrile for anchoring metal ions. Reactive \& Functional Polymers, 49(2), 133-143. http://dx.doi. org/10.1016/S1381-5148(01)00068-2.

32. Messier, P. J. (2005). US Patent 6,899,868. Washington: U.S. Patent and Trademark Office. Recuperado em 10 de julho de 2014, de http://patft.uspto.gov/netacgi/nphParser?Sect1=PT O1\&Sect $2=$ HITOFF $\& d=$ PALL $\& \mathrm{p}=1 \& \mathrm{u}=\% 2$ Fnetahtm $1 \% 2 \mathrm{~F}$ PTO\%2Fsrchnum.htm\&r=1\&f=G\&l=50\&s1=6,899,868.PN $. \& O S=P N / 6,899,868 \& R S=P N / 6,899,868$

33. Messier, P. J. (2004). US Patent No 6,680,050. Washington: U.S. Patent and Trademark Office. Recuperado em 10 de julho de 2014, de http://patft.uspto.gov/netacgi/nphParser?Sect1=P TO1\&Sect $2=$ HITOFF \&d=PALL $\& \mathrm{p}=1 \& \mathrm{u}=\% 2$ Fnetahtml $\% 2 \mathrm{~F}$ $\mathrm{PTO} \% 2 \mathrm{Fsrchnum} . \mathrm{htm} \& \mathrm{r}=1 \& \mathrm{f}=\mathrm{G} \& \mathrm{l}=50 \& \mathrm{~s} 1=6,680,050 . \mathrm{PN}$. $\& \mathrm{OS}=\mathrm{PN} / 6,680,050 \& \mathrm{RS}=\mathrm{PN} / 6,680,050$

34. Messier, P. J. (2003). US Patent No 6,592,821. Washington: U.S. Patent and Trademark Office. Recuperado em 10 de julho de 2014, de http://patft.uspto.gov/netacgi/nphParser?Sect1=P TO1\&Sect $2=$ HITOFF $\& d=$ PALL $\& p=1 \& u=\% 2$ Fnetahtm $1 \% 2 F$ $\mathrm{PTO} \% 2 \mathrm{Fsrchnum} . \mathrm{htm} \& \mathrm{r}=1 \& \mathrm{f}=\mathrm{G} \& \mathrm{l}=50 \& \mathrm{~s} 1=6,592,821 . \mathrm{PN}$ $\& O S=P N / 6,592,821 \& R S=P N / 6,592,821$

35. Shanbrom, E., Miekka, S. I., Pollock, R., Drohan, W. N., \& Horton, T. W. (2000). US Patent No 6,096,216. Washington: U.S. Patent and Trademark Office. Recuperado em 10 de julho de 2014, de http://patft.uspto.gov/netacgi/nphParser?Sect1=P TO1\&Sect $2=$ HITOFF $\& d=$ PALL $\& p=1 \& u=\% 2$ Fnetahtml $\% 2 F$ PTO\%2Fsrchnum.htm\&r=1\&f=G\&l=50\&s1=6,096,216.PN . $\& O S=P N / 6,096,216 \& \mathrm{RS}=\mathrm{PN} / 6,096,216$

36. Miekka, S. I., Drohan, W. N., Ralston, A., \& Xue, H. (2000). US Patent No 6,106,773. Washington: U.S. Patent and Trademark Office. Recuperado em 10 de julho de 2014, de http://patft. uspto.gov/netacgi/nphParser?Sect1 $=$ PT, 20O1\&Sect2 $=$ HITO $\mathrm{FF} \& \mathrm{~d}=\mathrm{PALL} \& \mathrm{p}=1 \& \mathrm{u}=\% 2 \mathrm{Fnetahtml} \% 2 \mathrm{FPTO} \% 2 \mathrm{Fsrchnum}$. $\mathrm{htm} \& \mathrm{r}=1 \& \mathrm{f}=\mathrm{G} \& \mathrm{l}=50 \& \mathrm{~s} 1=6,106,773 . \mathrm{PN} . \& \mathrm{OS}=\mathrm{PN} / 6,106,77$ $3 \& \mathrm{RS}=\mathrm{PN} / 6,106,773$

37. Messier, P. J. (2000). US Patent No 6,045,820. Washington: U.S. Patent and Trademark Office. Recuperado em 10 de julho de 2014, de http://patft.uspto.gov/netacgi/nphParser?Sect1=P TO1\&Sect $2=$ HITOFF $\& d=$ PALL $\& \mathrm{p}=1 \& u=\% 2$ Fnetahtml $\% 2 \mathrm{~F}$ $\mathrm{PTO} \% 2$ Frrchnum.htm\&r=1\&f=G\&l=50\&s1=6,045,820.PN $\& \mathrm{OS}=\mathrm{PN} / 6,045,820 \& \mathrm{RS}=\mathrm{PN} / 6,045,820$

38. Lund, J. L. (1995). US Patent No 5,431,908. Washington: U.S. Patent and Trademark Office. Recuperado em 10 de julho de 2014, de http://patft.uspto.gov/netacgi/nphParser?Sect1=PT O1\&Sect $2=$ HITOFF $\& d=$ PALL $\& \mathrm{p}=1 \& \mathrm{u}=\% 2 \mathrm{Fnetahtml} \% 2 \mathrm{~F}$ PTO\%2Fsrchnum.htm \& $\mathrm{r}=1 \& \mathrm{f}=\mathrm{G} \& \mathrm{l}=50 \& \mathrm{~s} 1=5,431,908 . \mathrm{PN}$ $. \& O S=P N / 5,431,908 \& R S=P N / 5,431,908$

39. Fina, L. R., Lambert, J. L., \& Bridges, R. L. (1991). US Patent No 4,999,190. Washington: U.S. Patent and Trademark Office. Recuperado em 10 de julho de 2014, de http://patft. uspto.gov/netacgi/nphParser?Sect $1=$ PTO1\&Sect $2=$ HITOF 
$\mathrm{F} \& \mathrm{~d}=\mathrm{PALL} \& \mathrm{p}=1 \& \mathrm{u}=\% 2 \mathrm{Fnetahtm} \mathrm{l} \% 2 \mathrm{FPTO} \% 2 \mathrm{Fsrchnum}$. htm\&r=1\&f=G\&l=50\&s1=4,999,190.PN.\&OS=PN/4,999,1 90\&RS $=$ PN/4,999, 190

40. Gartner, W. J. (1983). US Patent No 4,420,590. Washington: U.S. Patent and Trademark Office. Recuperado em 10 de julho de 2014, de http://patft.uspto.gov/netacgi/nphParser?Sect1=P TO1\&Sect $2=$ HITOFF $\& d=$ PALL $\& \mathrm{p}=1 \& \mathrm{u}=\% 2$ Fnetahtml $\% 2 \mathrm{~F}$ PTO\%2Fsrchnum.htm\&r=1\&f=G\&l=50\&s1=4,420,590.PN. $\& \mathrm{OS}=\mathrm{PN} / 4,420,590 \& \mathrm{RS}=\mathrm{PN} / 4,420,590$

41. Lambert, J. L., \& Fina, L. R. (1980). US Patent No 4,238,477. Washington: U.S. Patent and Trademark Office. Recuperado em 10 de julho de 2014, de http://patft.uspto.gov/netacgi/nphParser ?Sect $1=$ PTO1 $\&$ Sect $2=$ HITOFF $\& d=$ PALL $\& p=1 \& u=\% 2$ Fnetaht $\mathrm{ml} \% 2 \mathrm{FPTO} \% 2 \mathrm{Fsrchnum} . \mathrm{htm} \& \mathrm{r}=1 \& \mathrm{f}=\mathrm{G} \& \mathrm{l}=50 \& \mathrm{~s} 1=4,238,477$. PN.\&OS=PN/4,238,477\&RS $=$ PN/4,238,477

42. Hatch, G. L. (1980). US Patent No 4,190,529. Washington: U.S. Patent and Trademark Office. Recuperado em 10 de julho de 2014, de http://patft.uspto.gov/netacgi/nphParser?Sect1=P TO1\&Sect $2=$ HITOFF $\& d=$ PALL $\& \mathrm{p}=1 \& \mathrm{u}=\% 2$ Fnetahtml $\% 2 \mathrm{~F}$ PTO\%2Fsrchnum.htm\&r=1\&f=G\&l=50\&s1=4,190,529.PN. $\& O S=P N / 4,190,529 \& R S=P N / 4,190,529$

43. Lambert, J. L., \& Fina, L. R. (1975). US Patent No 3,923,665. Washington: U.S. Patent and Trademark Office. Recuperado em 10 de julho de 2014, de http://patft.uspto.gov/netacgi/nphParser ?Sect $1=$ PTO1\&Sect $2=$ HITOFF $\& d=$ PALL $\& p=1 \& u=\% 2$ Fnetaht $\mathrm{ml} \% 2 \mathrm{FPTO} \% 2 \mathrm{Fsrchnum} . \mathrm{htm} \& \mathrm{r}=1 \& \mathrm{f}=\mathrm{G} \& \mathrm{l}=50 \& \mathrm{~s} 1=3,923,665$. PN.\&OS=PN/3,923,665\&RS $=$ PN/3,923, 665

44. Lambert, J. L., \& Fina, L. R. (1974). US Patent No 3,817,860. Washington: U.S. Patent and Trademark Office. Recuperado em 10 de julho de 2014, de http://patft.uspto.gov/netacgi/nphParse $\mathrm{r}$ ?Sect $1=\mathrm{PTO} 1 \&$ Sect $2=$ HITOFF $\& \mathrm{~d}=\mathrm{PALL} \& \mathrm{p}=1 \& \mathrm{u}=\% 2 \mathrm{Fnetah}$ $\mathrm{tml} \% 2 \mathrm{FPTO} \% 2 \mathrm{Fsrchnum} . \mathrm{htm} \& \mathrm{r}=1 \& \mathrm{f}=\mathrm{G} \& \mathrm{l}=50 \& \mathrm{~s} 1=3817860$. PN.\&OS $=$ PN $/ 3817860 \& R S=P N / 3817860$

45. Gangadharan, D., Harshvardan, K., Gnanasekar, G., Dixit, D., Popat, K. M., \& Anand, P. S. (2010). Polymeric microspheres containing silver nanoparticles as a bactericidal agent for water disinfection. Water Research, 44(18), 5481-5487. http://dx.doi. org/10.1016/j.watres.2010.06.057. PMid:20673945.

46. Iconomopoulou, S. M., Andreopoulou, A. K., Soto, A., Kallitsis, J. K., \& Voyiatzis, G. A. (2005). Incorporation of low molecular weight biocides into polystyrene-divinyl benzene beads with controlled release characteristics. Journal of Controlled Release, 102(1), 223-233. http://dx.doi.org/10.1016/j.jconrel.2004.10.006. PMid: 15653147.

47. Muñoz-Bonilla, A., \& Fernández-García, M. (2012). Polymeric materials with antimicrobial activity. Progress in Polymer Science, 37(2), 281-339. http://dx.doi.org/10.1016/j. progpolymsci.2011.08.005.

48. Ahmed, A. E. I., Hay, J. N., Bushell, M. E., Wardell, J. N., \& Cavalli, G. (2008). Biocidal polymers (I): Preparation and biological activity of some novel biocidal polymers based on uramil and its azo-dyes. Reactive \& Functional Polymers, 68(1), 248-260. http://dx.doi.org/10.1016/j.reactfunctpolym.2007.09.004.

49. Allison, B. C., Applegate, B. M., \& Youngblood, J. P. (2007). Hemocompatibility of hydrophilic antimicrobial copolymers of alkylated 4-vinylpyridine. Biomacromolecules, 8(10), 29952999. http://dx.doi.org/10.1021/bm7004627. PMid:17877398.

50. Lu, G., Wu, D., \& Fu, R. (2007). Studies on the synthesis and antibacterial activities of polymeric quaternary ammonium salts from dimethylaminoethyl methacrylate. Reactive \& Functional Polymers, 67(4), 355-366. http://dx.doi.org/10.1016/j. reactfunctpolym.2007.01.008

51. Kurt, P., Wood, L., Ohman, D. E., \& Wynne, K. J. (2007). Highly effective contact antimicrobial surfaces via polymer surface modifiers. Langmuir, 23(9), 4719-4723. http://dx.doi. org/10.1021/la063718m. PMid:17388618.
52. Gabriel, G. J., Som, A., Madkour, A. E., Eren, T., \& Tew, G. N. (2007). Infectious disease: Connecting innate immunity to biocidal polymers. Materials Science and Engineering: R Reports, 57(1-6), 28-64. http://dx.doi.org/10.1016/j.mser.2007.03.002. PMid:18160969.

53. Murata, H., Koepsel, R. R., Matyjaszewski, K., \& Russell, A. J. (2007). Permanent, non-leaching antibacterial surface--2: how high density cationic surfaces kill bacterial cells. Biomaterials, 28(32), 4870-4879. http://dx.doi.org/10.1016/j. biomaterials.2007.06.012. PMid:17706762.

54. Kenawy, E.-R., Abdel-Hay, F. I., El-Magd, A. A., \& Mahmoud, Y. (2006). Biologically active polymers: VII. Synthesis and antimicrobial activity of some crosslinked copolymers with quaternary ammonium and phosphonium groups. Reactive \& Functional Polymers, 66(4), 419-429. http://dx.doi.org/10.1016/j. reactfunctpolym.2005.09.002

55. Cheng, Z., Zhu, X., Shi, Z. L., Neoh, K. G., \& Kang, E. T. (2005). Polymer microspheres with permanent antibacterial surface from surface-initiated atom transfer radical polymerization. Industrial \& Engineering Chemistry Research, 44(18), 70987104. http://dx.doi.org/10.1021/ie050225o.

56. Jiang, S., Wang, L., Yu, H., \& Chen, Y. (2005). Preparation of crosslinked polystyrenes with quaternary ammonium and their antibacterial behavior. Reactive \& Functional Polymers, 62(2), 209-213. http://dx.doi.org/10.1016/j.reactfunctpolym.2004.11.002.

57. Gelman, M. A., Weisblum, B., Lynn, D. M., \& Gellman, S. H. (2004). Biocidal activity of polystyrenes that are cationic by virtue of protonation. Organic Letters, 6(4), 557-560. http:// dx.doi.org/10.1021/ol036341+. PMid:14961622.

58. Park, E. S., Kim, H. S., Kim, M. N., \& Yoon, J. S. (2004). Antibacterial activities of polystyrene-block-poly(4-vinyl pyridine) and poly(styrene-random-4-vinyl pyridine). European Polymer Journal, 40(12), 2819-2822. http://dx.doi.org/10.1016/j. eurpolymj.2004.07.025.

59. Popa, A., Davidescu, C. M., Trif, R., Ilia, G., Iliescu, S., \& Dehelean, G. (2003). Study of quaternary 'onium' salts grafted on polymers: antibacterial activity of quaternary phosphonium salts grafted on 'gel-type' styrene-divinylbenzene copolymers. Reactive \& Functional Polymers, 55(2), 151-158. http://dx.doi. org/10.1016/S1381-5148(02)00224-9.

60. Li, G., \& Shen, J. (2000). A study of pyridinium-type functional polymers. IV. Behavioral features of the antibacterial activity of insoluble pyridinium-type polymers. Journal of Applied Polymer Science, 78(3), 676-684. http://dx.doi.org/10.1002/10974628(20001017)78:3<676::AID-APP240>3.0.CO;2-E.

61. Kanazawa, A., Ikeda, T., \& Endo, T. (1994). Polymeric phosphonium salts as a novel class of cationic biocides. VII. Synthesis and antibacterial activity of polymeric phosphonium salts and their model compounds containing long alkyl chains. Journal of Applied Polymer Science, 53(9), 1237-1244. http:// dx.doi.org/10.1002/app.1994.070530910.

62. Kanazawa,A., Ikeda, T., \& Endo, T. (1994). Polymeric phosphonium salts as a novel class of cationic biocides. VIII. Synergistic effect on antibacterial activity of polymeric phosphonium and ammonium salts. Journal of Applied Polymer Science, 53(9), 1245-1249. http://dx.doi.org/10.1002/app.1994.070530911.

63. Lambert, J. L., Fina, G. T., \& Fina, L. R. (1980). Preparation and properties of triiodide-, pentaiodide-, and heptaiodidequaternary ammonium strong base anion-exchange resin disinfectants. Industrial \& Engineering Chemistry Product Research and Development, 19(2), 256-258. http://dx.doi. org/10.1021/i360074a025.

64. Jandrey, A. C., Aguiar, A. P., Aguiar, M. R. M. P., Santa Maria, L. C., Mazzei, J. L., \& Felzenszwalb, I. (2007). Iodine-poly(2vinylpyridine-co-styrene-co-divinylbenzene) charge transfer complexes with antibacterial activity. European Polymer 
Journal, 43(11), 4712-4718. http://dx.doi.org/10.1016/j. eurpolymj.2007.07.042.

65. Jandrey, A. C., Santa Maria, L. C., Aguiar, A. P., Aguiar, M. R. M. P., Mazzei, J. L., \& Fenlzenszwalb, I. (2004). Iodine bactericidal action adsorbed in 2-vinylpyridine copolymer networks. Journal of Applied Polymer Science, 93(2), 972976. http://dx.doi.org/10.1002/app.20523.

66. Gazda, D. B., Lipert, R. J., Fritz, J. S., \& Porter, M. C. (2004). Investigation of the iodine-poly(vinylpyrrolidone) interaction employed in the determination of biocidal iodine by colorimetric solid-phase extraction. Analytica Chimica Acta, 510(2), 241247. http://dx.doi.org/10.1016/j.aca.2004.01.010.

67. Ahmed, A. E. I., Hay, J. N., Bushell, M. E., Wardell, J. N., \& Cavalli, G. (2008). Biocidal polymers (II): Determination of biological activity of novel N-halamine biocidal polymers and evaluation for use in water filters. Reactive \& Functional Polymers, 68(10), 1448-1458. http://dx.doi.org/10.1016/j. reactfunctpolym.2008.06.021.

68. Chen, Z., \& Sun, Y. (2006). N-halamine-based antimicrobial additives for polymers: preparation, characterization, and antimicrobial activity. Industrial \& Engineering Chemistry Research, 45(8), 2634-2640. http://dx.doi.org/10.1021/ ie060088a. PMid:18714370.

69. Barnes, K., Liang, J., Wu, R., Worley, S. D., Lee, J., Broughton, R. M., \& Huang, T. S. (2006). Synthesis and antimicrobial applications of 5,5'-ethylenebis[5-methyl-3-(3-triethoxysilylpropyl) hydantoin]. Biomaterials, 27(27), 4825-4830. http://dx.doi. org/10.1016/j.biomaterials.2006.05.023. PMid:16757023.

70. Liang, J., Chen, Y., Barnes, K., Wu, R., Worley, S. D., \& Huang, T.-S. (2006). N-halamine/quat siloxane copolymers for use in biocidal coatings. Biomaterials, 27(11), 2495-2501. http://dx.doi. org/10.1016/j.biomaterials.2005.11.020. PMid:16352336.

71. Chen, Y., Worley, S. D., Huang, T. S., Weese, J., Kim, J., Wei, C.-I., \& Williams, J. F. (2004). Biocidal polystyrene beads. IV. Functionalized methylated polystyrene. Journal of Applied Polymer Science, 92(1), 368-372. http://dx.doi.org/10.1002/ app. 20038.

72. Chen, Y., Worley, S. D., Kim, J., Wei, C.-I., Chen, T.-Y., Santiago, J. I., Williams, J. F., \& Sun, G. (2003). Biocidal poly(styrenehydantoin) beads for disinfection of water. Industrial \& Engineering Chemistry Research, 42(2), 280-284. http:// dx.doi.org/10.1021/ie020266+.

73. Kim, B. R., Anderson, J. E., Mueller, S. A., Gaines, W. A., \& Kendall, A. M. (2002). Literature review--efficacy of various disinfectants against Legionella in water systems. Water Research, 36(18), 4433-4444. http://dx.doi.org/10.1016/ S0043-1354(02)00188-4. PMid:12418646.

74. Eknoian, M. W., Worley, S. D., Bickert, J., \& Williams, J. F. (1999). Novel antimicrobial N-halamine polymer coatings generated by emulsion polymerization. Polymer, 40(6), 13671371. http://dx.doi.org/10.1016/S0032-3861(98)00383-8.

75. Sun, G., Allen, L. C., Luckie, E. P., Wheatley, W. B., \& Worley, S. D. (1995). Disinfection of water by N-halamine biocidal polymers. Industrial \& Engineering Chemistry Research, 34(11), 4106-4109. http://dx.doi.org/10.1021/ie00038a054.

76. Sun, Y., \& Sun, G. (2002). Synthesis, characterization, and antibacterial activities of novel N-halamine polymer beads prepared by suspension copolymerization. Macromolecules, 35(23), 8909-8912. http://dx.doi.org/10.1021/ma020691e.

77. Jeong, J.-H., Byoun, Y.-S., \& Lee, Y.S. (2002). Poly(styrenealt-maleic anhydride)-4-aminophenol conjugate: synthesis and antibacterial activity. Reactive \& Functional Polymers, 50(3), 257-263. http://dx.doi.org/10.1016/S1381-5148(01)00120-1.

78. Jeong, J.-H., Byoun, Y.-S., Ko, S.-B., \& Lee, Y. S. (2001) Chemical modification of poly(styrene-alt-maleic anhydride) with antimicrobial 4-aminobenzoic acid and 4-hydroxybenzoic acid. Journal of Industrial and Engineering Chemistry, 7(5), 310-315. Recuperado em 10 de julho de 2014, de http://www. cheric.org/PDF/JIEC/IE07/IE07-5-0310.pdf

79. Souza, M. A. V., Santa Maria, L. C., Costa, L. C., Galvão, R. C., Hui, W. S., \& Merçon, F. (2012). Evaluation of the biocide activity of phosphorylated and sulfophosphorylated resins. Materials Letters, 74(1), 121-124. http://dx.doi.org/10.1016/j. matlet.2012.01.093.

80. Costa, L. C., Marques, M. R. C., Tiosso, R. B., Cantarim, J. P., \& Merçon, F. (2012). Evaluation of the biocidal capacity of hypercrosslinked resins containing dithiocarbamate groups. Macromolecular Symposia, 319(1), 121-128. http://dx.doi. org/10.1002/masy.201100175.

81. Emerson, D. W. (1991). Slow release of active chlorine and bromine from styrene-divinylbenzene copolymers bearing $\mathrm{N}, \mathrm{N}$-dichlorosulfonamide, N-chloro-N-alkylsulfonamide, and $\mathrm{N}$-bromo-N-alkylsulfonamide functional groups. Polymer supported reagents. Industrial \& Engineering Chemistry Research, 30(11), 2426-2430. http://dx.doi.org/10.1021/ ie $00059 \mathrm{a} 010$.

82. Jaeger, W., Bohrisch, J., \& Laschewsky, A. (2010). Synthetic polymers with quaternary nitrogen atoms - Synthesis and structure of the most used type of cationic polyelectrolytes. Progress in Polymer Science, 35(5), 511-577. http://dx.doi. org/10.1016/j.progpolymsci.2010.01.002.

83. Santa Maria, L. C., Souza, J. D. C., Aguiar, M. R. M. P., Wang, S. H., Mazzei, J. L., Felzenszwalb, I., \& Amico, S. C. (2008). Synthesis, characterization, and bactericidal properties of composites based on crosslinked resins containing silver. Journal of Applied Polymer Science, 107(3), 1879-1886. http:// dx.doi.org/10.1002/app.27224.

84. Santa Maria, L. C., Oliveira, R. O., Merçon, F., Borges, M. E. R. S. P., Barud, H. S., Ribeiro, S. J. L., Messaddeq, Y., \& Wang, S. H. (2010). Preparation and bactericidal effect of composites based on crosslinked copolymers containing silver nanoparticles. Polímeros: Ciência e Tecnologia, 20(3), 227230. http://dx.doi.org/10.1590/S0104-14282010005000028.

85. Morones, J. R., Elechiguerra, J. L., Camacho, A., Holt, K., Kouri, J. B., Ramírez, J. T., \& Yacaman, M. J. (2005). The bactericidal effect of silver nanoparticles. Nanotechnology, 16(10), 2346-2353. http://dx.doi.org/10.1088/0957-4484/16/10/059. PMid:20818017.

86. Pal, S., Tak, Y. K., \& Song, J. M. (2007). Does the antibacterial activity of silver nanoparticles depend on the shape of the nanoparticle? A study of the Gram-negative bacterium Escherichia coli. Applied and Environmental Microbiology, 73(6), 1712-1720. http://dx.doi.org/10.1128/AEM.02218-06. PMid:17261510.

87. Oliveira, R. O. (2010). Preparação e avaliação biocida de compósitos à base de resinas reticuladas contendo nanopartículas de prata (Dissertação de mestrado). Universidade do Estado do Rio de Janeiro, Brasil.

88. Paschoalino, M. P., Marcone, G. P. S., \& Jardim, W. F. (2010). Os nanomateriais e a questão ambiental. Quimica Nova, 33(2), 421-430. http://dx.doi.org/10.1590/S0100-40422010000200033.

89. Braydich-Stolle, L., Hussain, S., Schlager, J. J., \& Hofmann, M. C. (2005). In vitro cytotoxicity of nanoparticles in mammalian germline stem cells. Toxicological Sciences, 88(2), 412-419. http://dx.doi.org/10.1093/toxsci/kfi256. PMid:16014736.

Enviado: Abr: 07, 2014

Revisado: Abr. 06, 2015 Aceito: Abr. 24, 2015 